\title{
A Communication Study on Using Emoticon of Adolescent with Developmental Disabilities
}

\author{
Wha-Soo Kim ${ }^{\text {a }}$, Soo-Yeon Shin ${ }^{\mathrm{b}}$ \\ ${ }^{a}$ Department of Speech Pathology, Daegu University, Gyeongsan, Korea \\ ${ }^{b}$ Department of Speech Pathology, Graduate School of Daegu University, Gyeongsan, Korea
}

\author{
Correspondence: Soo-Yeon Shin, MS \\ Department of Speech Pathology, Daegu \\ University, 201 Daegudae-ro, Jillyang-eup, \\ Gyeongsan 38453, Korea \\ Tel: $+82-53-850-4324$ \\ Fax: +82-53-850-4329 \\ E-mail: hyukemon@naver.com \\ Received: January 7, 2019 \\ Revised: February 13, 2019 \\ Accepted: March 7, 2019 \\ This research was supported by the Daegu \\ University Research Grants 2018. \\ This research was reconstructed by using the data \\ of Soo-Yeon Shin (2019).
}

\begin{abstract}
Objectives: The purpose of this study is to investigate the difference of KakaoTalk-emoticon cognition and understanding in adolescents with developmental disabilities (AWDD) and normal adolescents (NA). Methods: For survey analysis and two type of emoticon comprehension tests, we selected an AWDD group $(\mathrm{N}=20)$ and a NA group $(\mathrm{N}=20)$ who were in the same age group. Two types of evaluations were made to assess the understanding of the emoticon of the two groups at the AWDD group's expression language age average level. We also asked a response to the questionnaire on the use of emoticon for both groups. Results: There were no significant differences between the two groups in the results of the questionnaire on the perception and usage patterns of the KakaoTalk-emoticons. The results of two evaluations of the understanding of KakaoTalk-emoticons using auditory and visual cues showed that the NA group scored 3.35-3.5 points higher on average than the AWDD group. Conclusion: Based on the results of this study, it is necessary to encourage AWDDs to understand and express the correct emotions by providing them with education related to the understanding and use of emoticons.
\end{abstract}

Keywords: Adolescents with developmental disabilities (AWDD), KakaoTalk-emoticon, Emoticon cognition, Emoticon understanding ability, Communication
발달장애인이란, “장애인복지법” 제2조 제1항에서 규정하는 지 적장애인과 자폐성장애인을 의미한다(National Law Information Center, 2017). 발달장애인을 위한 정책으로 "발달장애인 권리보장 및 지원에 관한 법률”이 2017년도부터 시행됨에 따라 이들의 생애 주기에 따른 특성 및 복지 욕구에 적합한 지원과 권리옹호 등이 체 계적, 효과적으로 제공될 수 있도록 필요한 사항을 규정하였으며 발달장애인이 자신의 의사를 원활하게 표현할 수 있도록 지원해야 할 필요성이 증가하게 되었다. 이러한 사회적 패러다임에 따라 발달 장애인을 위한 적절한 의사소통 도구의 개발 및 전문인력의 양성과 함께 이들에게 의사소통과 관련된 교육 및 중재 연구 역시 그 중요 성이 높아지고 있다.

지적장애인과 자폐성장애인의 의사소통능력을 다룬 기존의 선행 연구들은 이들이 인지능력 또는 사회적 의사소통의 결함으로 인해 언어능력에서 양적 및 질적인 결함을 갖고 있음을 주장하며, 의사소 통 향상을 위하여 정확한 평가와 함께 적절한 중재가 이루어져야 함
을 역설하고 있다(Jin \& Pae, 2014; Kim, Kim, Kim, \& Song, 2018).

의사소통을 이루는 다양한 방법 중 비언어적 의사소통에 속하 는 이모티콘은 감정을 의미하는 'emotion'과 유사기호를 의미하는 ‘icon'의 합성어로, 인터넷 문화에서 네티즌들에 의해 활용되면서 간단하고 직관적인 메시지 전달방법으로 의사소통의 효율성을 높 이는 데에 기여하였으며, 시각적인 커뮤니케이션 도구로서 현대사 회에서 필수적인 의사소통 방법이 되었다. 또한 인터넷 문화와 모바 일 문화의 발전과 함께 social network service (SNS)가 등장하기 시 작하면서 급격히 성장해 왔는데 이는 사용자들의 생활에 있어 새로 운 방식의 어휘 사용을 급증시켰으며, 다양한 매체를 활용한 의사 소통 양상의 증가에 크게 기여해 왔다(An, 2018). 카카오톡은 이러 한 SNS 체제 중 매우 대중적인 스마트폰용 무료 통화 및 메신저 응 용 프로그램으로 현대 한국사회를 대표할 수 있는 의사소통 수단 으로서 자리매김하여 그 사용량이 점차 증가하는 추세이다(You, 2015). 
그동안의 이모티콘을 활용한 연구로는 이모티콘 사용 양상에 대 한 연구 또는 이모티콘의 기호학적 분석 연구가 대부분이었고(Ahn, 2014; Yun, 2017), 최근 장애를 가진 아동을 대상으로 이모티콘 관 련 연구가 단편적으로 수행되었다. Lee, Kim과 Yeon (2017)이 고기 능 자폐 아동의 화용능력 중재를 위해 이모티콘을 활용하였으며, $\mathrm{Bae}$ (2014)의 연구에서는 언어능력에 제한을 보이는 지적장애 아동 에게 SNS를 활용한 활동을 적용하였을 때 대상 아동의 자발적인 의사소통 행동이 증가되었음을 보고하였다. 또한 카카오톡 중재를 활용한 그룹 언어치료활동이 학령기 지적장애 아동의 화용능력 향 상에 긍정적인 영향을 미쳤음을 입증하기도 하였다(Song, 2016).

이러한 연구들을 바탕으로 본 연구에서는 한국인이 가장 많이 사용하는 카카오톡 메신저의 이모티콘 활용에 대한 설문과 듣기 단서, 그림 단서를 제공한 이해력 평가를 통해 발달장애 청소년의 이모티콘 사용과 관련된 의사소통을 탐색하고자 하였다. 이를 위 해 다음과 같은 연구문제를 설정하였다.

(1) 발달장애 청소년과 생활연령을 맞춘 일반 청소년의 카카오톡 이모티콘 사용 양상은 어떠한가?

(2) 발달장애 청소년과 생활연령을 맞춘 일반 청소년은 청각적 단 서 제공에 따른 이모티콘 이해력과 시각적 단서 제공에 따른 이모티콘 이해력에서 차이를 보이는가?

\section{연구방법}

\section{연구대상}

본 연구의 대상군은 “발달장애인법”에서 규정하는 장애로 진단 받았으며, "청소년기본법”에 따라 생활연령이 만 24세 이하에 해당 하는 발달장애 청소년(adolescents with developmental disabilities, $\mathrm{AWDD}$ ) 20 명으로 구성하였다. 대조군의 경우 자가보고 시 언어능 력, 시각 및 청각의 감각, 정서 및 행동과 운동 발달에 있어 문제가 없는 청소년으로 대상군과 생활연령을 일치시킨 일반 청소년(normal adolescents, NA) 20명으로 구성하였다.

$\mathrm{AWDD}$ 집단의 경우 $\mathrm{NA}$ 집단 $(\mathrm{N}=20$, 생활연령 평균 $=19 ; 9, \mathrm{SD}=$ 1.15)과 동등한 교육과정을 수료하였으며, $\mathrm{K}$ 시 발달장애인 고등교 육기관(일반대학 과정과 동일한 대학 과정)에 입학한 자로 학력평 가 결과에 따라 동일한 학년체제에 재학 중인 학생들 중 카카오톡 애플리케이션 및 대화기능 사용이 가능하며, 설문지 문항 및 글 이 해가 가능한 학생 $(\mathrm{N}=20$, 생활연령 평균 $=19 ; 9, \mathrm{SD}=1.57)$ 으로 선 발하였다.

보건복지부 통계연보(Ministry of Health and Welfare, 2018)에 따르면, 전국의 지적장애인은 101,175 명, 자폐성 장애인은 24,698 명
Table 1. Participants' characteristics

\begin{tabular}{|c|c|c|c|c|}
\hline \multirow{2}{*}{ No. } & \multirow{2}{*}{$\begin{array}{c}\text { Chronological } \\
\text { age (yr:mo) }\end{array}$} & \multirow{2}{*}{$\begin{array}{l}\text { Degree of } \\
\text { disability }\end{array}$} & \multicolumn{2}{|c|}{ Language age (yr;mo) } \\
\hline & & & Receptive $^{a}$ & Expressive $^{a}$ \\
\hline 1 & $19 ; 10$ & ID level 3 & $6 ; 0-6 ; 5$ & $9 ; 0-9 ; 5$ \\
\hline 2 & $19 ; 1$ & ID level 3 & $10 ; 0-10 ; 5$ & $8 ; 6-8 ; 11$ \\
\hline 3 & $18 ; 9$ & ASD level 3 & $12 ; 0-12 ; 5$ & $14 ; 0-14 ; 5$ \\
\hline 4 & $19 ; 9$ & ID level 3 & $14 ; 0-14 ; 5$ & Over 16;0 \\
\hline 5 & $19 ; 6$ & ID level 3 & $10 ; 0-10 ; 5$ & $11 ; 0-11 ; 5$ \\
\hline 6 & $19 ; 5$ & ID level 2 & $6 ; 0-6-5$ & $6 ; 6-6 ; 11$ \\
\hline 7 & $19 ; 0$ & ID level 2 & $9 ; 0-9 ; 5$ & $8 ; 0-8 ; 5$ \\
\hline 8 & $19 ; 3$ & ASD level 3 & $15 ; 0-15 ; 5$ & $11 ; 0-11 ; 5$ \\
\hline 9 & $20 ; 10$ & ID level 3 & $4 ; 6-4 ; 11$ & $6 ; 0-6 ; 5$ \\
\hline 10 & $20 ; 2$ & ASD level 3 & $9 ; 0-9 ; 5$ & $9 ; 0-9 ; 5$ \\
\hline 11 & $21 ; 2$ & ASD level 2 & $9 ; 0-9 ; 5$ & $7 ; 6-7 ; 11$ \\
\hline 12 & $19 ; 9$ & ID level 3 & $9 ; 6-9 ; 11$ & $8 ; 6-8 ; 11$ \\
\hline 13 & $19 ; 1$ & ID level 3 & $10 ; 0-10 ; 5$ & $11 ; 0-11 ; 5$ \\
\hline 14 & $20 ; 9$ & ASD level 3 & $14 ; 0-14 ; 5$ & Over 16;0 \\
\hline 15 & $19 ; 9$ & ID level 2 & 10;0-10;5 & $11 ; 0-11 ; 5$ \\
\hline 16 & $24 ; 5$ & ID level 3 & Over 16;0 & Over 16;0 \\
\hline 17 & $19 ; 8$ & ID level 3 & $12 ; 0-12 ; 5$ & $10 ; 0-10 ; 5$ \\
\hline 18 & $19 ; 5$ & ID level 3 & $13 ; 0-13 ; 5$ & $9 ; 0-9 ; 5$ \\
\hline 19 & $19 ; 11$ & ID level 3 & 8;6-8;11 & $7 ; 6-7 ; 11$ \\
\hline 20 & $24 ; 7$ & ID level 2 & $10 ; 0-10 ; 5$ & $10 ; 0-10 ; 5$ \\
\hline
\end{tabular}

Degree of disability= the level of disability in Korea; $I D=$ intellectual disability; $A S D=$ autism spectrum disorders.

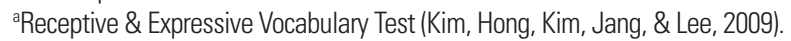

이다. 이 비율을 근거로 하여 본 연구에서는 15 명의 지적장애(intellectual disability) 청소년과, 5 명의 자폐성장애(autism spectrum disorders) 청소년으로 AWDD 대상자를 선발하였다. AWDD 집단 의 특성은 Table 1 과 같다.

\section{연구도구}

\section{이모티콘 관련 설문조사}

본 연구의 설문지는 연구대상자들의 이모티콘 사용 실태를 파악 하기 위해 Ahn (2014)의 부록을 참조하여 제작한 뒤 2018년 3월 중 순부터 4 월 초순 사이 20 개의 문항으로 예비연구를 실시하였다. 이 후 문항 재조정 과정을 거쳐 총 17 문항으로 설문지를 수정-완료하 였다. 설문지 문항의 분류 기준은 Table 2에 제시하였다.

\section{이모티콘 이해력 측정 평가}

본 연구에서는 연구대상자들의 이모티콘 이해력을 평가하기 위 해 두 가지 단서(듣기 단서, 그림 단서)를 제공하는 이모티콘 이해력 평가지를 제작하기 위해 우선 대상자들이 카카오톡으로 대화를 하면서 이해하거나 표현할 수 있는 감정을 4 가지 범주의 감정(희로 
Table 2. Questionnaire question classification

\begin{tabular}{ll}
\hline Question & \multicolumn{1}{c}{ Criteria } \\
\hline $01,02,03,06$ & Frequency of use of KakaoTalk \& emoticons \\
04,05 & Reason for using emoticons \\
07 & Types of emoticons used \\
08,09 & people who talk most often using KakaoTalk \& emoticons \\
$010,011,012,013$ & Frequency of using emoticons to convey a particular emotion \\
014,015 & Purchase of paid emoticons \\
016,017 & Satisfaction with and willingness to use KakaoTalk \& emoticons \\
\hline
\end{tabular}

Table 3. Types of emoticons provided by KakaoTalk

\begin{tabular}{l} 
Emoticon type \\
\hline Text and communication language-type \\
Image-type
\end{tabular}

애락)으로 분류하였다. 카카오톡에서는 사용자에게 다양한 종류 의 이모티콘을 제공하고 있으며, Table 3에 이를 제시하였다. 이 중 에서 카카오톡에서 공식적으로 무료 제공하고 있는 그래픽형 이모 티콘(기본 이미지 이모티콘 및 플래쉬몹 이모티콘) 각 5 문항(총 20 문항)과 텍스트형 이모티콘(한글·자모·유니코드 혼합형) 가운데 각 5 문항(총 20 문항)씩 수집하여 40 개의 문항으로 제작하였다. 제 작과정의 경우 Figure 1에 제시되어 있다.

검사 내용과 난이도를 조정하기 위해 $\mathrm{AWDD}$ 집단의 평균 언어 연령대(10-12세)에 해당하는 일반 초등학생 15명을 대상으로 2018 년 3월 중순부터 4 월 초순 사이 한 평가당 20 개의 문항으로 예비연 구를 실시하였다.

예비연구 결과, 희로애락 감정에서 $90 \%$ 이상 정반응률이 나왔던 문항을 네 가지 감정당 각 2 문항씩 8 문항으로 구성하였다. 그 다음 $80 \%-90 \%$ 의 정반응률을 보였던 12 문항을 혼합하여 본 검사 내용 과 난이도를 조정하였다. 이후 1 급 언어재활사 자격소지자 2 명의 내 용타당도에 대한 검증작업을 시행하였으며 이러한 작업을 통해 듣 기 단서를 제공한 이해력 평가와 시각 단서를 제공한 이해력평가 문항에 각각 예비 1 문항을 추가하여 한 평가당 총 21 문항으로 최종 문항을 구성하였다.

각 평가지별로 제공된 단서(듣기 단서, 그림 단서)에 따른 예시문 항은 Figures 2, 3과 같다.
Step 1

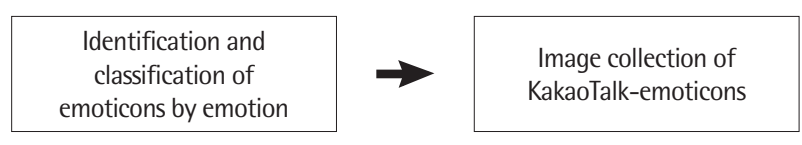

Step 2
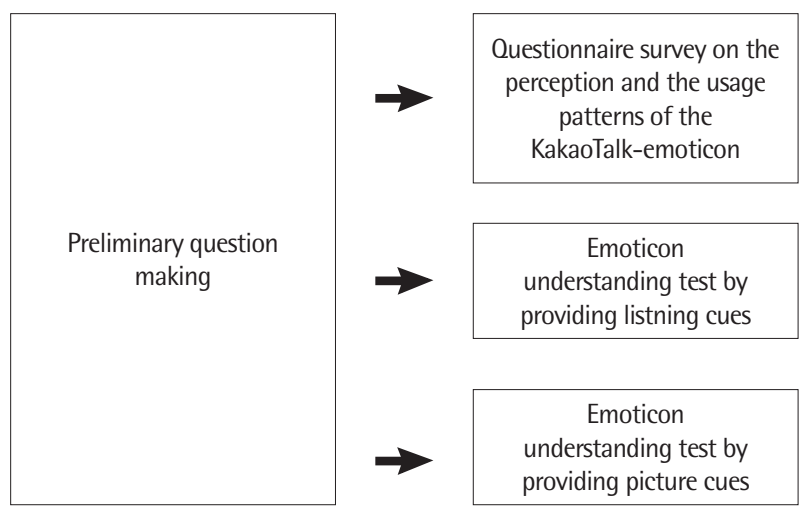

Emoticon understanding test by providing picture cues

Step 3

Preliminary research

Step 4

Readjustment of questionnaires and exam papers

Figure 1. Production process of research tools.

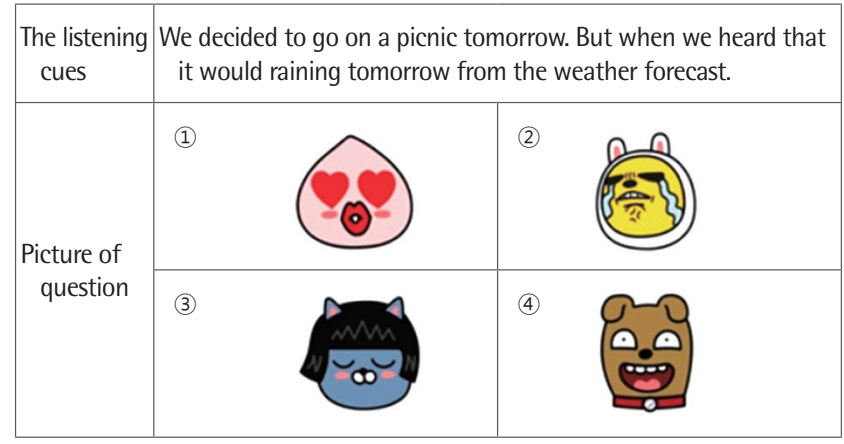

Figure 2. Example of an emoticon understanding test by providing listening cue.

\section{연구절차 및 자료분석}

선발된 AWDD 집단과 생활연령을 일치시킨 NA 집단(각 20명, 총 40 명)을 최종 설문 대상자로 선정하여 이모티콘 설문조사 및 이 모티콘 이해력 평가 2종을 실시하였다. 모든 조사 및 평가는 외부 와 단절되어 소음이 적은 공간에서 연구자와 대상자가 일대일로 


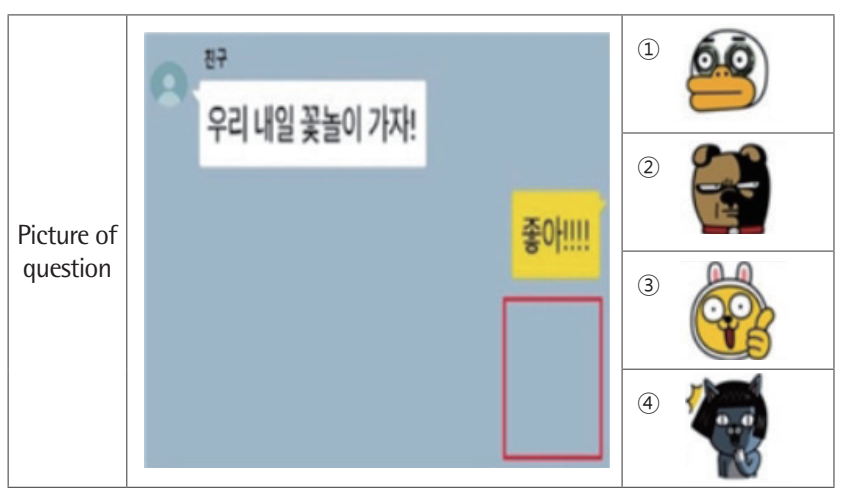

Figure 3. Example of an emoticon understanding test by providing picture cue.

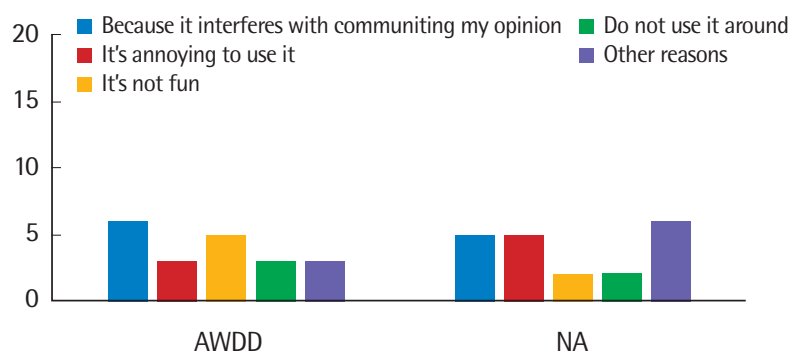

Figure 4. Factors preventing the use of emoticons in KakaoTalk.

AWDD=adolescents with developmental disabilities; $\mathrm{NA}=$ normal adolescents.

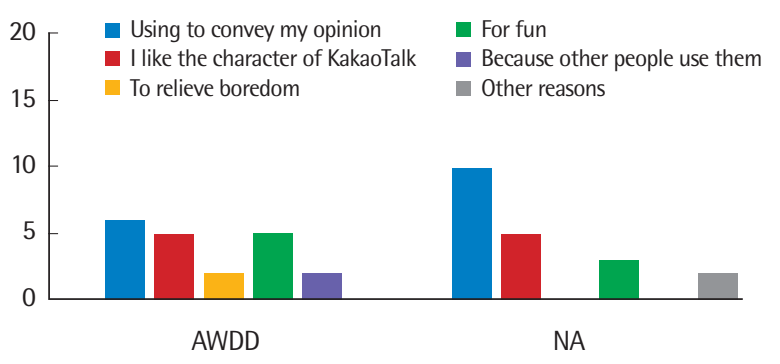

Figure 5. Factors that using emoticons in KakaoTalk.

AWDD=adolescents with developmental disabilities; $N A=$ normal adolescents

마주보고 앉아 실시하였으며 빈도와 백분율로 나타내기 어려운 문항의 경우 추가로 심층 면접을 가져 대상자들의 응답을 받았다. 그림 단서를 제공한 이모티콘 이해력 평가와 설문조사는 개별로 답안지와 설문지를 제공하여 대상자 스스로 응답하게 하였다. 듣 기 단서를 제공한 이모티콘 이해력 평가는 평가자가 파워포인트 프로그램으로 각 문항의 그림보기를 제시하면서 특정 상황을 들 려준 뒤 대상자의 답변을 듣고 받아 적는 방법으로 진행되었고, 이 모든 과정은 녹화를 통해 보조적 기록을 시행하였다. 각 평가가 끝 난 후에 휴식시간을 제공하였으며, 총 1 시간 30 분이 소요되었다. 본 연구의 통계처리는 SPSS version 24.0 (IBM, Armonk, NY, USA)

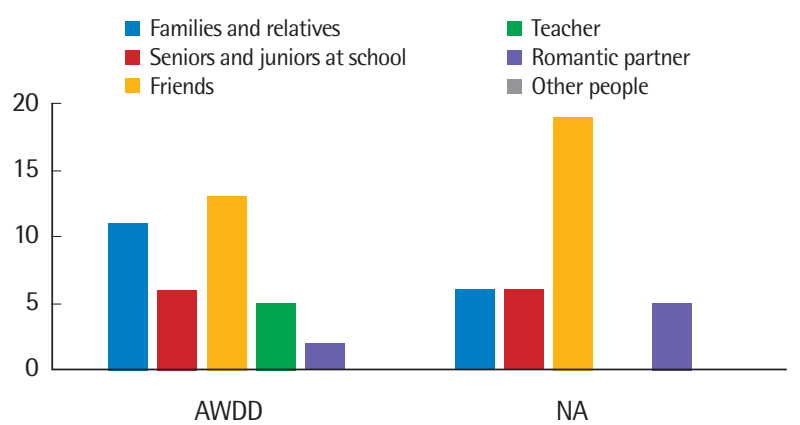

Figure 6. People who talk most often in KakaoTalk (included overlapping answers). AWDD =adolescents with developmental disabilities; $N A=$ normal adolescents.

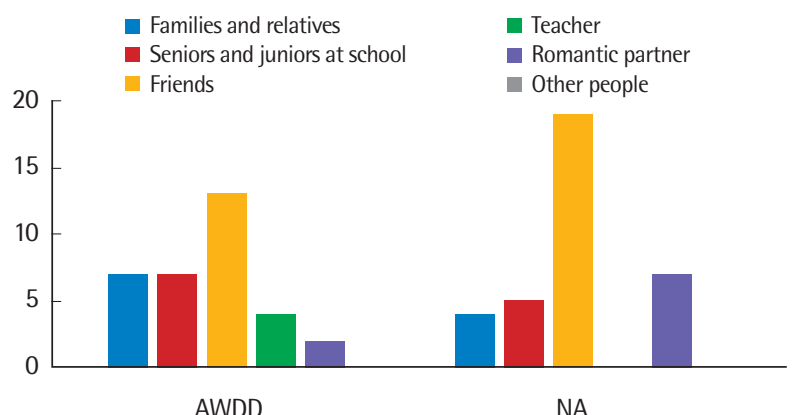

Figure 7. People who send most often in KakaoTalk (included overlapping answers).

$\mathrm{AWDD}=$ adolescents with developmental disabilities; $N A=$ normal adolescents.

을 이용하여 분석하였다. 두 집단 간에 2종류의 단서를 제공한 이 해력 평가 결과가 상관관계가 있는지를 살펴보기 위해 각 집단의 평가점수 결과를 수치화한 다음 독립표본 $t$-검정을 실시하였고, 두 가지 단서를 제공한 이해력 평가 점수에서 이모티콘 문항에서 감 정유형 및 형태에 따른 응답 비율을 알아보고자 Fisher의 정확 검 정을 실시하였다.

\section{연구결과}

\section{발달장애 청소년과 일반 청소년의 이모티콘 사용 실태 및 양상}

$\mathrm{AWDD}$ 집단과 NA 집단(각 20명, 총 40명)을 대상으로 실시한 이모티콘 사용 양상과 관련된 설문조사 결과의 경우 두 집단 간에 유의미한 차이가 보이지 않았으며, Figures 4-7과 같이 유사한 양상 으로 나타났다.

카카오톡 이모티콘을 사용하지 않는 이유를 살펴보았을 때, ‘나 의 의견을 전달하는 데 방해가 되기 때문에'라는 항목을 발달장애 청소년 집단은 1 순위로, 일반 청소년 집단은 2 순위로 가장 많이 선 택하였다(Figure 4). 카카오톡 이모티콘을 사용하는 이유로는 두 


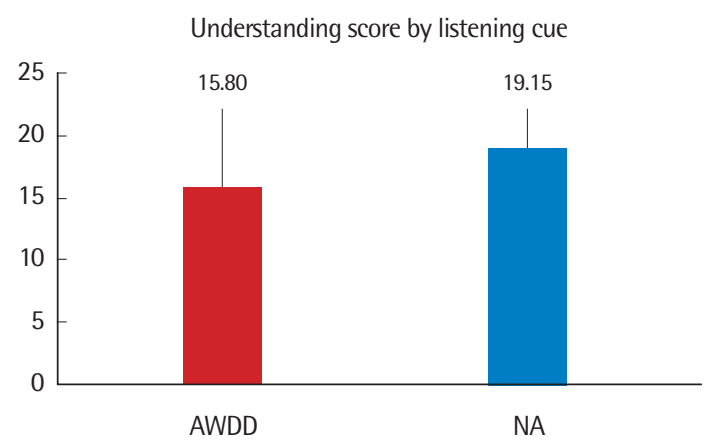

Figure 8. Comparison of emoticon comprehension score by listening cue. AWDD=adolescents with developmental disabilities; $N A=$ normal adolescents .

집단 모두 ‘나의 의사표현을 전달하는 데 사용하려고’라는 항목을 가장 많이 선택하였다(Figure 5).

Figure 6은 누구와 카카오톡을 가장 많이 사용하는지에 대한 응 답을 나타내며, Figure 7은 누구에게 대화할 때 이모티콘을 가장 많 이 전송하는지에 대한 응답을 나타낸다. 두 집단 모두 친구와 대화 하기 위해 카카오톡을 가장 많이 사용하며 이모티콘의 사용량도 이에 비례하고 있음을 알수 있었다.

\section{발달장애 청소년과 일반 청소년의 듣기 단서와 그림 단서 제공에 의한 이모티콘 이해력 비교}

집단 간 이해력 평균점수 비교

두 집단별로 두 가지 단서 제공에 따른 이해력 평가 점수들을 독 립표본 $t$-검정으로 분석한 결과는 Figures 8,9 와 같다. 듣기 단서를 제공한 이해력 평가에서 $\mathrm{AWDD}$ 집단의 평균은 $15.80(\mathrm{SD}=1.79)$, 생활연령을 일치시킨 NA 집단의 평균은 $19.15(\mathrm{SD}=0.67)$ 로, $\mathrm{NA}$ 집단보다 AWDD 집단의 이모티콘 이해력이 유의미하게 낮은 것으 로 나타났으며 $(t=-7.819, p<.001)$, 그림 단서를 제공한 이해력 평가 시, $\mathrm{AWDD}$ 집단의 평균은 $15.95(\mathrm{SD}=2.16)$, 생활연령을 일치시킨 $\mathrm{NA}$ 집단의 평균은 $19.45(\mathrm{SD}=0.60)$ 로, 듣기 단서를 제공한 이해력 평가 결과와 마찬가지로 $\mathrm{AWDD}$ 집단의 이모티콘 이해력이 NA 집 단보다 유의미하게 낮은 것으로 나타났다 $(t=-6.967, p<.001)$.

\section{듣기 단서를 제시한 이모티콘 이해력 평가 결과 내 4가지 감정별 정반응률 비교}

이모티콘의 4 가지 감정 범주와 관련하여 듣기단서를 제공한 이 해력 평가점수의 경우, 이모티콘의 이해력 평가점수에 이모티콘의 감정형태가 영향을 미치는지를 검증하고자 하였으나 $\mathrm{AWDD}$ 집단 구성원의 이해력 점수 분포가 5점 미만의 경우로 나타난 경우가 많 아, Fisher의 정확 검정을 실시하여 분석하였다. '기쁨 $\left(\chi^{2}=15.734\right.$,

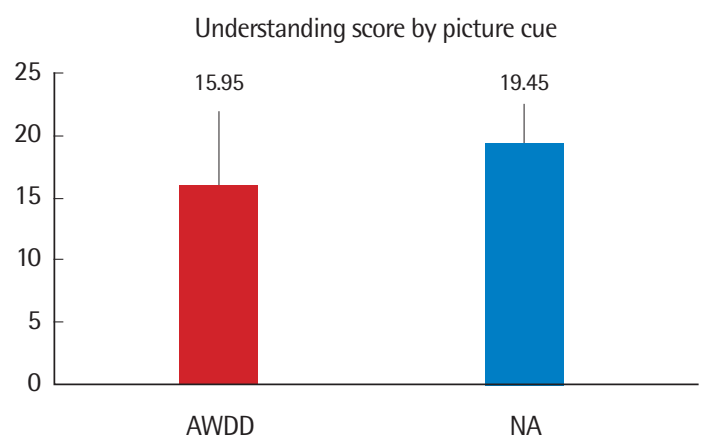

Figure 9. Comparison of emoticon comprehension score by picture cue. AWDD=adolescents with developmental disabilities; NA=normal adolescents .

$p=.000)$,' '노여움 $\left(\chi^{2}=9.591, p=.005\right)$,' '슬픔 $\left(\chi^{2}=15.205, p=.001\right)$ ' 감정에서는 $\mathrm{AWDD}$ 집단이 $\mathrm{NA}$ 집단에 비해 유의미하게 이해력 점 수가 낮았다. '즐거움 $\left(\chi^{2}=4.217, p=.232\right)$ ' 감정에서는 유의미한 차 이가 나타나지 않았다.

듣기 단서를 제시한 이모티콘 이해력 평가 결과 내 3가지 형태별 정반응률 비교

이모티콘의 3 가지 형태 범주와 관련하여 듣기 단서를 제공한 이 해력 평가점수의 경우 이모티콘의 4 가지 감정 범주와 관련한 분석 의 결과와 마찬가지로, '이미지형 $\left(\chi^{2}=12.248, p=.007\right)$ ', '플래시몹 형 $\left(\chi^{2}=7.598, p=.039\right)$ ', '문자. 통신언어형 $\left(\chi^{2}=21.692, p=.000\right)$ ' 문 항 모두 NA 집단이 $\mathrm{AWDD}$ 집단에 비해 높은 점수를 나타내었다.

그림 단서를 제시한 이모티콘 이해력 평가 결과 내 4가지 감정별 정반응률 비교

그림 단서를 제공하는 이모티콘 이해력 평가 결과에서도 문항이 나타내는 4 가지 감정 범주가 대상군과 대조군의 정반응률에 영향 을 미치는지를 분석하였다. Fisher의 정확 검정을 실시하여 분석한 결과, '기쁨 $\left(\chi^{2}=16.303, p=.000\right)$ ', '슬픔 $\left(\chi^{2}=17.942, p=.000\right)$ ', '노여 움 $\left(\chi^{2}=18.309, p=.000\right)$, '즐거움 $\left(\chi^{2}=9.394, p=.003\right)$ '에 해당하는 모든 감정에서 $\mathrm{NA}$ 집단이 $\mathrm{AWDD}$ 집단보다 높은 점수를 나타내었 고, 이는 유의미하였다.

그림 단서를 제시한 이모티콘 이해력 평가 결과 내 3가지 형태별 정반응률 비교

그림 단서를 제공한 이모티콘 이해력 평가 결과에서 문항이 나타 내는 이모티콘의 3 가지 형태 범주에 따라 대상군 및 대조군의 정반 응률 비율이 어떻게 나뉘어지는가를 분석하였다. Fisher의 정확 검 정을 실시하여 분석하였을 때, '이미지형 $\left(\chi^{2}=8.256, p=.024\right)$ ', '문 
자. 통신언어형 $\left(\chi^{2}=23.635, p=.000\right)^{\prime}$ 에서는 $\mathrm{NA}$ 집단에 비해 $\mathrm{AWDD}$ 집단이 낮은 점수 분포를 나타냈으나, '플래시몹형 $\left(\chi^{2}=2.161, p=.492\right)$ ' 문항에서의 두 집단의 점수 차이는 유의미하지 않았다. 특히 점수 분포 결과 중 문자.통신언어형 이모티콘 문항의 경우, $\mathrm{AWDD}$ 집 단이 NA 집단에 비해 훨씬 더 광범위한 점수분포를 나타냄과 동시 에 낮은 점수를 기록하였기 때문에 일반 청소년에 비해 발달장애 청소년이 문자. 통신언어형 이모티콘을 이해하기 더 어려워한다는 사실을 반영한다고 볼수 있다.

\section{논의 및 결론}

본 연구에서는 발달장애 청소년들과 생활연령을 일치시킨 일반 청소년들을 대상으로 카카오톡 이모티콘과 관련된 설문조사를 통 해 이들의 이모티콘에 대한 인식 및 사용 양상을 알아보고자 하였으 며, 두 가지 단서를 제공한 이모티콘 이해력 평가들을 통해 발달장애 청소년의 이모티콘 이해력에 대해 알아보고 일반 청소년과 그 차이 가 어떠한지를 살펴보았다. 이에 따른 논의 및 결론은 다음과 같다.

\section{발달장애 청소년과 일반 청소년의 이모티콘 사용 실태 및 양상}

첫째, 카카오톡 이모티콘을 사용하는 이유를 묻는 질문에 두 집 단 모두 ‘나의 의사표현을 전달하는 데 사용하려고’라는 항목을 가 장 많이 선택하였다. 이는 Park (2005)의 연구결과와 일치하는 것이 다. Park (2005)은 이모티콘이 글쓴이의 감정을 표현하지만 동시에 메시지를 보는 상대의 감정을 직접 유도한다는 점에서 상호적이며, 온라인 대화에서 상대에게도 유사한 감정을 불러일으키기 때문에 텍스트에 감정을 부여하고 대화 참여자들이 관계에 보다 적극적으 로 개입하는 역할을 한다고 하였다. 즉 학생들이 의사소통의 효율 성을 높이기 위해 스스로 판단하에 이모티콘을 사용하거나 사용 하지 않는다는 것을 알 수 있었다. 누구에게 이모티콘을 가장 많이 사용하는지를 물었을 때, 두 집단 구성원 모두 ‘친구'라는 항목을 가장 많이 선택하였다. 이러한 결과는 화자가 의사소통하는 상대 와 정서적인 친밀감을 표현하는 의도로 이모티콘을 사용한다는 주 장을 제기하였던 학설의 내용을 지지하는 것이다(Hwang \& Park, 2008; Philippot \& Feldman, 2004). 발달장애 청소년에게는 이모티 콘을 활용하는 것이 자신의 의사를 바르게 표현하기 위한 수단으 로 중대한 것이 될 수 있다. 상대방과 소통하는 과정에서 발생할 수 있는 감정을 다룬다는 점에서도 중요한 사안이 될 수 있다. 발달장 애인들의 긍정적인 정서 표현뿐 아니라 부정적인 정서를 언어나 이 모티콘으로 순화할 수 있는 방법을 가르치는 것은 의사소통 중재 의 한 측면으로 작용할 수 있을 것이다.

\section{두 가지 단서를 제공한 카카오톡 이모티콘 이해력 평가 결과에서의 주요 시사점}

\section{듣기 단서를 제공한 카카오톡 이모티콘 이해력 평가}

듣기 단서를 제공하여 실시한 이모티콘 이해력 평가 결과를 분석 했을 때, 일반 청소년이 발달장애 청소년보다 3.35점가량 더 높은 평균점수를 보였고, 이는 유의하였다 $(t=-7.819, p<.001)$.

오류를 보인 해당 발달장애 청소년들에게 자신이 응답한 항목에 대해 설명해 보라고 했을 때 대체적으로 각 문제가 나타내는 감정 을 바르게 인지하고 있었다. 단지 이를 의미하는 이모티콘의 형태 및 모양을 바르게 변별하지 못해서 오답을 보였던 것이었다. 이러한 오류는 전체 오답률 중 $50 \%$ 이상을 차지하였다.

자폐 또는 지적장애 아동이 일반아동에 비해 기본 정서의 변별 에 어려움을 더 많이 보인다는 대부분의 연구들과는 달리 자폐아 동의 정서 이해 및 지각을 다루었던 몇몇의 연구결과는 자폐아동 이 얼굴 표정을 통한 기본 정서 인식에 어려움을 보이지 않았다고 보고한다(Choi, 2005; Kim, Kim, \& Lee, 2013). 본 연구의 대상이었 던 발달장애 청소년들이 대부분의 감정을 바르게 인지하고 있었다 는 사실은 특정 상황을 감정의 원인으로 이해하는 데 어려움이 없 었음을 의미한다. 이는 발달장애인들이 행복과 슬픔을 인식하는 데 있어 결함을 보이지 않았다고 예측하였던 연구결과와도 맥을 같이하는 것이다(Baron-Cohen, Spitz, \& Cross, 1993).

\section{그림 단서를 제공한 카카오톡 이모티콘 이해력 평가}

그림 단서 제공에 따른 이모티콘 이해력 평가 결과를 분석했을 때, 일반 청소년이 발달장애 청소년보다 3.5점 더 높은 평균점수를 보였고, 이는 유의한 차이를 나타냈다 $(t=-6.697, p<.001)$.

오류 문항을 보였던 해당 발달장애 청소년들에게 응답 이유와 실제로 문제에서 느껴지는 감정이 무엇인지를 물었을 때에는 듣기 단서를 제공한 이해력 평가 결과의 오답유형과 동일한 원인으로 오 답률이 높게 나타났다.

이러한 발달장애 청소년 대상자 중, 자폐성장애로 진단받은 피험 자 10 번의 경우 자신이 좋아하는 캐릭터(예: 토끼)가 포함된 보기가 포함된 문항을 보면, “제가 좋아하는 무지(캐릭터)에요.”라고 말하 며, 토끼 그림이 들어간 보기나 정답만 선택하여 응답하는 경향을 보였다. 해당 피험자의 취득점수에서 오답이었던 문항이 10 문제 중 5 문제에 달하였다. 또 다른 피험자 8 번의 경우에는 자폐성장애로 진단받았음에도 불구하고, 그림 단서 제공에 따른 문항의 경우 20 점 중 19 점으로 높은 점수를 기록하기도 하였다.

즉, 본 연구를 통해 반복해서 알 수 있었던 것은 발달장애 청소년 이 일반 청소년에 비해 SNS상의 정서를 표현하는 대화 상황 및 맥 
락에서 비언어적인 도구수단으로 이해될 수 있는 이모티콘을 이해 하는 것에서 점수는 낮게 측정되었으나 발달장애 청소년들 개인 간 의 차이가 오히려 크게 존재하고 있음을 알 수 있었다.

\section{감정 범주에 의한 두 가지 단서 과제에서 이해력 평가}

듣기 단서와 그림 단서를 제시한 이해력 평가 결과들이 이모티콘 이 나타내는 4 가지 감정(희로애락) 종류에서 대부분의 감정에서 발 달장애 청소년들이 더 낮은 점수를 취득하였다. 두 가지 단서를 통 한 이해력 평가들의 결과에 있어 발달장애 청소년들의 오반응률이 일반 청소년들보다 더 높았던 이유는 앞서 이해력 결과 분석 내용 에서 언급한 것처럼 이모티콘의 형식과 그에 맞는 어휘를 인지하고 선택하는 것이 바르게 되지 않았기 때문이었다.

지적장애 아동의 표현언어의 발달이 비장애 아동의 언어발달과 유사하더라도 10 세 이후가 되면서 비장애 아동들과 질적으로 다 른 언어 발달 형태를 보인다고 밝혔던 Kim (2010)의 연구결과와 함 께 초기 언어 발달에 있어 지적장애를 가진 아동들이 전형적인 발 달을 하는 아동들의 발달과 비교하였을 때 유사하기는 하지만 느 린 발달 경로를 보인다는 사실을 밝힌 연구 가설 내용을 본 연구와 비교해 볼 필요가 있다(Boudreau \& Chapman, 2000). 즉 본 연구 는 발달장애 청소년이 일반 청소년에 비해 여전히 의사소통에서 발 달이 느리다는 것을 시사해 준다.

\section{형태 범주에 의한 두 가지 단서 제공에 따른 이해력 평가}

듣기 단서와 그림 단서를 제시한 이해력 평가 결과들을 이모티콘 의 형태 기준에 따라 분석하였을 때 두 집단 모두 이미지형 이모티 콘에서 정답률이 높았고, 장애로 인해 정반응률이 영향을 받는 것 에 통계적으로 유의미한 결과가 도출되었다. 발달장애 청소년 집단 의 두 가지 단서 과제의 이해력 평가에서 35점 미만으로 낮은 점수 가 나왔던 문항의 유형들을 보면 전체 오답률을 나타냈던 문항의 $83.33 \%$ 가 문자. 통신언어형 이모티콘 형태였다. 일례로 발달장애 청소년 피험자 6 번의 경우 문자로 이루어진 4 문항이 모두 오답이었 지만 이모티콘의 형태가 이미지형이거나, 플래시몹형인 문항이 주 어졌을 경우에는 모두 정답을 찾을 수 있었다. 발달장애 청소년들 은 감정을 바르게 인지할 수 있더라도 이를 표현하는 이모티콘 형 식을 구별하지 못하는 경향이 있었으며 특히 타유형에 비해 문자. 통신언어형 이모티콘을 어려워한다는 것을 알 수 있었다.

Jeon (2012)은 지적장애 아동에게 그림카드와 퍼즐식 그림카드 를 이용한 언어 중재를 제공하였을 때 지적장애 아동의 수용어휘 력 향상에 유의미하게 효과적이었다는 연구결과를 제시하였다. 이 는 언어 중심적인 방법에 의해 기억을 유도하는 메시지 활용보다 그
림을 통해 정보를 직접 인식하고 지각의 장을 구성하게 하는 것이 발달장애인에게는 더욱 효과적인 중재방법이 될 수 있다는 사실을 시사하는 것이다.

본 연구의 결과는 이를 뒷받침하며 발달장애인에게 이모티콘을 활용한 의사소통 향상 관련 중재를 제공할 때는 문자형 이모티콘 보다 시각적인 이미지로 이루어져 있는 이모티콘을 활용하는 것이 바람직할 것으로 생각된다.

\section{본 연구의 제한점 및 제언}

본 연구결과에 따른 제한점과 후속연구를 위한 제언을 제시하고 자한다.

첫째, 본 연구에서는 설문지와 두 가지 단서 제공을 통한 평가로서 발달장애 청소년 집단의 이모티콘을 활용한 의사소통 양상과 이들 의 이모티콘 이해력에 대한 평가점수 결과를 제시하였다. 하지만 발 달장애 청소년 집단의 이모티콘 표현력에 대한 평가 및 의사소통 양 상까지 살펴보지 못했다. 후속연구에서는 이들의 이모티콘 표현력과 감정표현 양상에 대한 또 다른 분석을 추가로 진행할 필요가 있다.

둘째, 본 연구의 대상 중 장애군은 지적장애와 자폐성장애로 한 정되어 있고, 각 집단을 대표하기에 인원수가 충분하지 못하다는 한계가 있다. 또한 AWDD 집단과 대조군인 NA 집단 간 유사한 학 력을 보유하였기 때문에 두 집단의 언어연령 평균에 차이가 존재하 더라도 해당 생활연령 대에서 요구되는 학습능력 및 생활능력을 보유한 것으로 간주하여 생활연령 평균만 일치시켜 실험을 하였다. 후속연구에서는 대상군 및 대조군의 구성을 확대하고, 언어연령을 고려한 연구를 진행할 예정이다. 또한 발달장애 청소년들 내에서 자폐성장애와 지적장애 간 차이를 탐색하는 것도 흥미로운 연구가 될 수 있으리라 생각된다.

셋째, 본 연구에서 활용되었던 이모티콘의 종류 및 형태에서 한 계가 있었다. 카카오톡에서 제공하는 이모티콘 및 문자형 이모티콘 을 최대한 활용하기는 하였으나 일부 유료 이모티콘은 다뤄지지 못 했다. 좀 더 다양한 형태와 많은 수의 이모티콘을 균등한 비율로 조 절하여 후속연구가 이루어질 필요가 있다.

본 연구는 발달장애 청소년을 대상으로 폭넓은 의사소통을 연 구하기 위한 시도를 했다는 것에 의미가 있다. 이 결과를 바탕으로 발달장애 청소년 및 발달장애 성인을 위한 의사소통 중재의 기초 가 되기를 기대한다.

\section{REFERENCES}

Ahn, D. H. (2014). A study on actual condition and perception of emoticon use 
among college students (Master's thesis). Yeungman University, Gyeongsan, Korea.

An, H. S. (2018). A study on the written expression of vocabulary in social network service (SNS) of adolescents with developmental disabilities (Master's thesis). Daegu University, Gyeongsan, Korea.

Bae, J. H. (2014). A study on the aspect of communication and spontaneous communication behavior for students with developmental disabilities through social network service activities (Master's thesis). Daegu University, Gyeongsan, Korea.

Baron-Cohen, S., Spitz, A., \& Cross, P. (1993). Do children with autism recognise surprise? A research note. Cognition \& Emotion, 7(6), 507-516.

Boudreau, D. M., \& Chapman, R. S. (2000). The relationship between event representation and linguistic skill in narratives of children and adolescents with Down syndrome. Journal of Speech, Language, and Hearing Research, 43(5), 1146-1159.

Choi, J. H. (2005). A study on emotional perception of high-functioning autistic children (Master's thesis). Daegu University, Gyeongsan, Korea.

Hwang, H. S., \& Park, S. B. (2008). College student's usage of emoticons in mobile text-based messaging. Media, Gender \& Culture, 9, 133-192.

Jeon, G. E. (2012). Effect of language intervention using picture cards and puzzle-picture cards on receptive vocabulary abilities in children with intellectual disability: focus on noun and verb (Master's thesis). Wonkwang University, Iksan, Korea.

Jin, Y. S., \& Pae, S. (2014). Communication profiles of school-aged children with social communication disorder and high-functioning autism. Communication Sciences \& Disorders, 19(1), 45-59.

Kim, C. H., Kim, Y. T., \& Lee, S. J. (2013). Effect of context and affective prosody on emotional perception in children with high-functioning autism. Communication Sciences \& Disorders, 18(1), 24-34.

Kim, H. H., Kim, Y. T., Kim, J. A., \& Song, S. H. (2018). Pragmatic language characteristics of children with mild intellectual disabilities using audio- visual discourse tasks (KOPLAC). Communication Sciences \& Disorders, 23(2), 298-312.

Kim, Y. H. (2010). Promoting methods for augmentative \& alternative communication of investigation with intellectual disabled children (Doctoral thesis). Daegu University, Gyeongsan, Korea.

Kim, Y. T., Hong, G. H., Kim, K. H., Jang, H. S., \& Lee, J. Y. (2009). Receptive \& expressive vocabulary test (REVT). Seoul: Seoul Community Rehabilitation Center.

Lee, S. H., Kim, Y. T., \& Yeon, S. J. (2017). Expression and preference of emoticons in SNS contexts in children with high-functioning autism spectrum disorder. Journal of Speech-Language \& Hearing Disorders, 26(2), 99-112.

Ministry of Health and Welfare. (2018). Status of registration for the disabled (December 2017). http://www.mohw.go.kr/react/jb/sjb030301vw.jsp?PAR_ MENU_ID=03\&MENU_ID=0321\&CONT_SEQ=344589\&page=1.

National Law Information Center. (2017). Law on the Protection and Support of People with Developmental Disabilities (Law No. 14839). http://www.law. go.kr/lsInfoP.do?lsiSeq=195992\&efYd=20170726\#0000.

Park, H. K. (2005). Relationship between emoticons and nonverbal behaviors in online chatting system: emoticons as relational control mechanism. Journal of Communication Science, 5(3), 273-302.

Philippot, P., \& Feldman, R. S. (2004). The regulation of emotion. Mahwah, NJ: Lawrence Erlbaum Associates.

Song, S. Y. (2016). The effects of group language therapy program including Kakaotalk appllication on the pragmatic competence of school aged children with intellectual disability (Master's thesis). Daegu University, Gyeonsan, Korea.

You, S. G. (2015). Create something out of nothing. http://news.chosun.com/ site/data/html_dir/2015/12/22/2015122202671.html.

Yun, M. H. (2017). A study on the sign \& visual symbols of Kakao Talk emoticons. Journal of the Korean Society of Design Culture, 23(2), 443-455. 


\section{국문초록}

\section{발달장애 청소년의 이모티콘을 활용한 의사소통 연구}

김화수 ${ }^{1}$ 신수연 ${ }^{2}$

'대구대학교 언어치료학과, ${ }^{2}$ 대구대학교 일반대학원 재활과학과 언어치료전공

배경 및 목적: 본 연구는 발달장애 청소년과 일반 청소년을 대상으로 카카오톡 이모티콘에 대한 인식 및 사용양상과 이모티콘의 이해 력에 차이가 있는지를 알아보고자 하였다. 방법: 발달장애 청소년 집단을 선정하여 이들의 수용 및 표현언어연령 평균 수준에 맞게 이 모티콘 이해력을 평가할 수 있는 평가지 2 종을 제작하였고, 대상 집단과 생활연령을 일치시킨 일반 청소년 집단을 선별하여 두 집단을 대상으로 이모티콘 사용 관련 설문조사와 두 가지 단서 제공에 따른 이모티콘 이해력에 관한 평가를 실시하였다. 결과: 카카오톡 이모 티콘에 관한 인식과 사용 양상을 알아보는 설문조사 결과에서는 두 집단이 유의미한 차이를 보이지 않았다. 듣기 단서와 그림 단서를 각각 제공하였던 두 가지 방법의 카카오톡 이모티콘의 이해력 평가 결과에서는 두 평가 결과 모두 20 점 만점 기준으로 일반 청소년 집단 이 발달장애 청소년 집단보다 약 3.35-3.5점 더 높은 평균점수를 나타냈다. 또한 두 가지 단서 제공에 따른 이모티콘 이해력 평가 결과에 영향을 미치는 요인들 중 이모티콘을 구성하는 4 가지 감정에 따른 분석에서는 대부분의 감정에서 발달장애 청소년 집단의 이해력이 일 반 청소년 집단보다 낮게 측정되었다. 이모티콘의 형태를 기준으로 이해력 평가 결과들을 분석하였을 때 두 집단 모두 이미지형 이모티 콘이 사용된 문항에서 정답률이 높았다. 논의 및 결론: 본 연구결과에 따라 발달장애 청소년의 의사소통을 향상시키기 위한 방안으로 이모티콘을 활용한 이해 및 사용과 관련된 교육을 제공함으로써 자신의 감정을 바르게 이해하고, 표현할 수 있도록 중재해야 할 필요 가 있다.

핵심어: 발달장애 청소년, 카카오톡 이모티콘, 이모티콘 이해력, 의사소통

본논문은 대구대학교 2018년도 학술연구비 지원을 받아 수행된 연구임.

본 연구는 제2저자의 2019년 연구 데이터를 활용하여 재구성하였음.

\section{참고문헌}

국가법령정보센터(2017). 발달장애인 권리보장 및 지원에 관한 법률(법률 제14839호). http://www.law.go.kr/lsInfoP.do?lsiSeq= 195992\&efYd= 2017 0726\#0000.

김연희(2010). 지적장애인의 보완·대체의사소통 중재 방략. 대구대학교 대학원 박사학위논문.

김영태, 홍경훈, 김경희, 장혜성, 이주연(2009). 수용·표현어휘력검사(REVT). 서울: 서울장애인종합복지관.

김찬희, 김영태, 이수정(2013). 맥락 및 운율에 따른 고기능 자폐아동의 정서 이해 특성. Communication Sciences \& Disorders, 18(1), 24-34.

김현희, 김영태, 김정아, 송승하(2018). 시청각 담화과제(KOPLAC)를 통한 경도 지적장애 아동의 화용언어 특성. Communication Sciences \& Disor-

ders, 23(2), 298-312.

박현구(2005). 온라인 환경의 이모티콘과 비언어 행위의 관계: 관계통제로서의 이모티콘. 언론과학연구, 5(3), 273-302.

배정혜(2014). 소셜네트워크서비스 활동을 통한 발달장애학생의 의사소통 양상과 자발적 의사소통행동 변화에 관한 연구. 대구대학교 대학원 석사

학위논문.

보건복지부(2018). 장애인 등록 현황(2017년 12월말 기준). http://www.mohw.go.kr/react/jb/sjb030301vw.jsp?PAR_MENU_ID=03\&MENU_

$\mathrm{ID}=0321 \&$ CONT_SEQ $=344589$ \&page $=1$.

송선영(2016). 카카오톡 어플 중재를 포함한 그룹언어치료 활동이 학령기 지적장애 아동의 화용능력에 미치는 효과. 대구대학교 대학원 석사학위논문. 안대현(2014). 대학생의 이모티콘 사용실태와 인식조사. 영남대학교 대학원 석사학위논문.

안효상(2018). 발달장애 청소년의 소셜 네트워크 서비스(SNS)에 나타난 어휘 표기 연구. 대구대학교 석사학위 논문. 
유슬기(2015). 카카오톡 이모티콘의 핵심은 콤플렉스. http://news.chosun.com/site/data/html_dir/2015/12/22/2015122202671.html.

윤민희. (2017). 카카오톡 이모티콘의 기호체계 및 상징에 관한 연구. 한국디자인문화학회지, 23(2), 443-455.

이수현, 김영태, 연석정(2017). 고기능 자폐 아동의 SNS 대화 맥락에서 유생성에 따른 이모티콘 정서 표현 능력 및 선호도 분석. 언어치료연구, 26(2),

99-112.

전고은(2012). 그림카드와 퍼즐식 그림카드를 이용한 언어중재가 지적장애 아동의 수용 어휘력에 미치는 효과: 명사, 동사 중심으로. 원광대학교 대 학원 석사학위논문.

진연선, 배소영(2014). 학령기 사회적의사소통장애와 고기능 자폐 아동의 의사소통 능력 차이. Communication Sciences \& Disorders, 19(1), 45-59. 최정희(2005). 고기능 자폐아의 정서 지각에 관한 연구. 대구대학교 대학원 석사학위논문.

황하성, 박성복(2008). 문자메시지의 이모티콘 활용에 관한 연구. 미디어, 젠더 \& 문화, 9, 133-162.

\section{ORCID}

김화수(http://orcid.org/0000-0003-4787-4824); 신수연(http://orcid.org/0000-0002-5216-8118) 